\title{
Assessing log geometry and wood quality in standing timber using terrestrial laser-scanning point clouds
}

\section{Pyorala, Jiri}

2019-04

Pyorala , J , Kankare , V , Liang , X, Saarinen , N , Rikala , J , Kivinen , V-P , Sipi , M , Holopainen, M , Hyyppa , J \& Vastaranta , M 2019 , ' Assessing log geometry and wood quality in standing timber using terrestrial laser-scanning point clouds ' , Forestry , vol. 92 , no. 2 , pp. 177-187 . https://doi.org/10.1093/forestry/cpy044

http://hdl.handle.net/10138/309232

https://doi.org/10.1093/forestry/cpy044

unspecified

acceptedVersion

Downloaded from Helda, University of Helsinki institutional repository.

This is an electronic reprint of the original article.

This reprint may differ from the original in pagination and typographic detail.

Please cite the original version. 


\title{
Assessing log geometry and wood quality in standing timber using terrestrial laser-scanning point clouds
}

\author{
Jiri Pyörälä1,2,3*, Ville Kankare ${ }^{1,2}$, Xinlian Liang ${ }^{2,3}$, Ninni Saarinen ${ }^{1,2}$, Juha \\ Rikala $^{1}$, Veli-Pekka Kivinen ${ }^{1}$, Marketta Sipi ${ }^{1}$, Markus Holopainen ${ }^{1,2}$, Juha \\ Hyyppä2,3, Mikko Vastaranta $^{1,2,4}$
}
${ }^{1}$ Department of Forest Sciences, University of Helsinki, Helsinki, FI-00014, Finland
${ }^{2}$ Centre of Excellence in Laser Scanning Research, Finnish Geospatial Institution, Masala, FI- 02431, Finland
${ }^{3}$ Department of Remote Sensing and Photogrammetry, Finnish Geospatial Institution, Masala, FI-02431, Finland

${ }^{4}$ School of Forest Sciences, University of Eastern Finland, Joensuu, FI-80101, Finland

*Corresponding author: Tel: +358503608183; Email: jiri.pyorala@helsinki.fi

\begin{abstract}
Wood procurement in sawmills could be improved by resolving detailed three-dimensional stem geometry references from standing timber. This could be achieved, using the increasingly available terrestrial point clouds from various sources. Here, we collected terrestrial laser-scanning (TLS) data from 52 Scots pines (Pinus sylvestris L.) with the purpose of evaluating the accuracy of the log geometry and analysing its relationship with wood quality. For reference, the log-specific top-end diameter, volume, tapering, sweep, basic density and knottiness were measured in a sawmill. We produced stem models from the TLS data and bucked them into logs similar to those measured in the sawmill. In comparison to the sawmill data, the log-specific TLS-based top-end diameter, volume, taper and sweep estimates showed relative mean differences of $1.6 \%,-2.4 \%,-3.0 \%$, and $78 \%$, respectively. The correlation coefficients between increasing taper and decreasing wood density and whorl-to-whorl distances were 0.49 and 0.51 , respectively. Although the stem-model geometry was resolved from the point clouds with similar accuracy to that at the sawmills, the remaining uncertainty in defining the sweep and linking the wood quality
\end{abstract}


with stem geometry may currently limit the method's feasibilities. Instead of static TLS, mobile platforms would likely be more suitable for operational point cloud data acquisition.

\section{Introduction}

Sawmills account for stem dimensions and shape in optimizing the two-phase breakdown of stems into logs and sawn goods. Primary log breakdown (or bucking) is carried out according to a demand matrix that defines the allowable log length and top-end diameter combinations, as well as the desired number of logs in a given dimension category (Kivinen and Uusitalo, 2002). The secondary log breakdown (or sawing) is based on either optical or X-ray scanning data or both (Lundgren, 2000; Nordmark and Oja, 2004; Oja et al., 2004; Fredriksson, 2014), which in addition to log dimensions, also accounts for shape attributes, such as stem taper and sweep. Log dimension and shape properties restrict the choice of sawing pattern, i.e., they introduce constraints to an optimization problem of maximizing the timber volume sawn from a log (Nordmark, 2005). Both excessive log tapering and sweep are known to reduce the timber volume (Taylor and Wagner, 1996; Yerbury and Cooper, 2010). Moreover, stem geometry also indicates the expected wood quality; e.g., log sweep has been linked with increased reaction wood content (Rune and Warensjö, 2002). On the other hand, stem taper may indicate certain cellular wood properties (Lindström, 1996). For example, vigorous trees that have long live crowns exhibit strong tapering and increased proportions of juvenile wood (core wood, or crown wood) in the xylem (Lindström, 1996; Fabris, 2000). Juvenile wood has, among its other differences, lower wood density and higher microfibril angle in the secondary cell-wall middle layer and, as a result, lower strength and stiffness than matured wood (outer wood, or stem wood) (Burdon et al., 2004).

Sawmills can use their databases of log geometry and wood quality for wood procurement planning, i.e. for timing and targeting the harvesting operations. Simulated sawing of virtual sawlogs reconstructed from the sawmill databases is currently the most detailed approach to optimizing log breakdown according to the properties of a specific batch of logs (Todoroki, 1990; Pinto et al., 2006; Auty et al., 2014). In addition, sawing simulators could enable estimating of optimal log breakdown patterns and sawn wood product recoveries from potential harvest sites, based on remote sensing (Barth et al., 2015; Sanz et al., 2018), if proper references from the standing timber were available. Due to the natural variability of wood quality between and within stands and individual trees (Björklund, 1997; Huuskonen et al., 2014; Ojansuu et al., 2018), the optimal references, i.e. inputs to sawing simulators, would describe the tree-specific stem geometry as a three-dimensional (3-D) stem model that could be virtually bucked, and linked with the wood quality data (Mäkelä et al., 2010).

The emergence of various sensors and platforms for acquiring high-resolution 3-D point cloud data from a forest environment could enable measurement of the standing timber's stem geometry with the level of detail required in log breakdown optimization (Wallace et al., 2012; Liang et al., 2015; Liang et al., 2018b). While operationally functional systems (e.g. systems integrated in harvesters) are still under development, terrestrial laser-scanning (TLS) performed from a static platform is currently the most precise system for use in a forested environment and thus a viable tool for researching point cloud - based applications (Maas et al., 2008; Liang et al., 2016). Previous studies have investigated the applicability of TLS point clouds to stem modelling and demonstrated several 
quantitative approaches that would enable highly automated retrieval of the stem geometry from standing timber in a forest environment (Liang et al., 2012; Raumonen et al., 2013; Hackenberg et al., 2014; Mengesha et al., 2015; Xia et al., 2015; de Conto et al., 2017). The following studies used harvester data as references to evaluate the accuracy of point cloud- based stem-model geometry or product recovery estimations: Murphy et al. (2010) used TLS-derived stem curves to estimate the primary log breakdown product recovery and reported standard errors of $7 \%$ and $8 \%$ for treespecific values and volume yields, respectively. Kankare et al. (2014) used allometric stem taper models based on generic tree descriptors derived from TLS point clouds and estimated the sawlog volume with $17.5 \%$ root-mean-squared error (RMSE). Liang et al. (2014) reported RMSEs of $1.13 \mathrm{~cm}$ and $29.3 \mathrm{dm}^{3}$ for TLS stem-model diameter and volume estimations, respectively.

On the contrary, studies considering the relationship of TLS-derived stem-model geometry with wood quality data from sawmills are lacking. However, Van Leeuwen et al. (2011) reviewed the feasibility of using TLS point clouds to assess wood quality, and Stängle et al. (2014) were able to predict the clear-wood content of European beech (Fagus sylvatica L.) stems by analysing the stem shape and presence of branch scars. It is thus reasonable to assume that linking detailed structural measurements from high-density point clouds of standing timber with sawmill data could enable more sophisticated preharvest optimization of log breakdown. The minimal technical requirements for combining point cloud-based stem models and sawmill wood quality data for simulated sawing include that the log geometry derived from the point clouds must concur with the state-of-the-art in the sawmills and express logical relationships with wood quality.

In this study, we aimed at examining the feasibilities of high-density terrestrial point cloud data contributing to preharvest log breakdown optimization. We evaluated the accuracy of top-end diameter, volume, tapering and sweep of logs measured from stem-model geometry based on TLS point clouds in comparison to the respective sawmill measurements that set the level for the operational applications, and analysed the relationship between log geometry and interior wood quality.

\section{Methods}

Study area

Our study area encompassed a 1.7-ha stand located in Orivesi, southern Finland (latitude $61^{\circ} 51^{\prime} 13^{\prime \prime}$ $\mathrm{N}$, longitude $024^{\circ} 13^{\prime} 7^{\prime \prime} \mathrm{E}$, elevation $\sim 150 \mathrm{~m}$ above sea level) (Figure 1 ). The stand was comprised of homogenous Scots pine-dominated, mainly Vaccinium-type subxeric heath forest that was sown in 1950 (Table 1). The selected stand represented a commonly available source of softwood timber in southern Finland. The latest national forest inventory in 2013 showed that $54 \%$ of the area with mature forests in Finland was Scots pine-dominated and that $43 \%$ of the annually harvested sawlog timber was Scots pine. The stand description based on a stand-wise forest inventory from 2015 is given in Table 1.

\section{Sample trees, terrestrial laser scanning data acquisition, and stem modelling}

In all, 52 Scots pine sample trees were selected in 10 groups of 2-5 trees distributed evenly to cover the entire stand. The trees were selected to represent the diameter distribution of the stand. Each tree was marked with an identification (ID) number to enable later recognition. The TLS survey was carried out on July 3, 2016. The nearest Finnish Meteorological Institute weather station showed 
that the average wind speed on that day was less than $3 \mathrm{~m} / \mathrm{s}$. The terrestrial laser scanner used was a Trimble TX5 (Trimble Inc., Sunnyvale, CA, USA) phase-shift scanner. With the scanning resolution used, the point-to-point sampling distance at $10 \mathrm{~m}$ from the scanner was $3.1 \mathrm{~mm}$. Quality parameter 2 was used, which means that each measured point was an average of two distance measurements. Each tree group was scanned from 3-7 locations, with the scanner mounted on a tripod. The scanning locations were adjusted specifically for each tree group to obtain full data coverage on all sides of the trees. In all, we acquired 33 scans, with the scanning time being 7 min 9 s per scan (total work time with two operators: $8 \mathrm{~h}$ ). Six target spheres (radii $9.8 \mathrm{~cm}$ ) were set on tripods around the scanned trees to enable later coregistration of the individual scans into a common, local coordinate system.

The point clouds were prefiltered and coregistered, using the built-in procedures in Faro Scene 5.4 software (Faro Technologies Inc., Lake Mary, FL, USA). Points with fewer than two other points within a $3 \times 3$-cell grid in the two-dimensional (2-D) projection neighbourhood and points with intensity values lower than 300 (on a scale of 0-2084) were filtered out.

The sample trees were identified, based on the ID numbers and extracted manually from the coregistered point clouds. The height of the root collar was estimated visually, and the points below that height were excluded. Points belonging to a stem were identified as flat, vertical structures and modelled by means of a cylinder-fitting method using a 20-cm vertical interval (Liang et al., 2012). To enable interpolation of the stem diameters and centre locations between the measuring points, a smoothing cubic spline (stats; smooth.spline $(R, 2018)$ ) was applied to the measured stem diameters and stem centre $x$ - and $y$-coordinates as a function of height. The smoothing parameter of the spline function was set to 0.4 ( on a scale of $0-1$, where 0 means the spline crosses through every point in the original data and 1 is equal to a linear least-squares approximation), based on the sensitivity analysis carried out in Saarinen et al. (2017). The smoothing spline was also used to extrapolate the stem diameters beyond the last measured height up to the tree height $(\mathrm{H})$, which was defined as the difference between the lowest and highest return in the manually extracted point cloud. The resulting stem taper curves of the sample trees are presented in Figure 2.

\section{Harvesting and sawmill measurements}

The study site was clear-cut in July 2016, and the trees were cut-to-length in the forest, based on the bucking matrix of the sawmill in Korkeakoski (UPM-Kymmene Oyj, Helsinki, Finland). The minimum allowed sawlog top-end diameter was $15 \mathrm{~cm}$ (over-bark). The allowable sawlog lengths ranged between $428 \mathrm{~cm}$ and $548 \mathrm{~cm}$ at 30-cm intervals. The sawlogs bucked from the sample trees were marked with ID numbers and kept separate from the remaining logs. This was done to enable linking the log-specific data with the respective stem models produced from the TLS point clouds. The harvester produced 103 sawlogs from the 52 sample trees: 52 butt logs, 42 middle logs and 9 top logs.

The sample logs were measured at the sawmill in August 2016. The tree number and order of log (i.e. butt, middle, top) were identified, based on their ID numbers. The measurements included two scanning repetitions with the sawmill equipment. The log-scanning system in use was a Visiometric LignaProfi (Visiolog Ltd., Lappeenranta, Finland) system that entails four static laser beams and three 
directions. The diagrams entailed the log diameters and centre points with a resolution of $5 \mathrm{~cm}$ in vertical direction that were used to calculate the top-end diameter, volume, taper and sweep of each log (Figure 3 ). The top-end diameter was the average of the top-end diameters of the three directions. The volume of a log was calculated as the volume of a truncated cone, using the log length and averaged over-bark diameters at the top-end and at the $2 / 3$ length of the log (from the top-end). Taper $(\mathrm{mm} / \mathrm{m})$ was defined as the difference between the averaged log top-end over-bark diameter and over-bark diameter at the $2 / 3$ length, divided by the length of the log. Sweep $(\mathrm{mm} / \mathrm{m})$ was determined as the maximum deviation of the surface model centre line from the log centre line (i.e. a direct line from the top-end centre point down to the centre point at the $2 / 3$ length of the log) in any of the three measurement directions. The diameter and centre point at the $2 / 3$ length of the log were used instead of those of the bottom-end to deduct the butt-swelling that will be planed off before the logs are sawn.

To enable the interpretation of interior wood quality, a Wood-X 4D Tomo (Finnos Ltd., Lappeenranta, Finland) X-ray scanning device (digital radiographer) was used to estimate the basic density of the sapwood and to detect whorls present in the heartwood in each log. In X-ray scanning, the X-ray beams were transmitted through a log from four directions, and the attenuation values were used to image the log's cross section at a given point along the log in two dimensions (2-D). The series of consecutive cross-sectional images were combined into a comprehensive reconstruction of the log, with $10 \mathrm{~mm} \times 10 \mathrm{~mm} \times 10 \mathrm{~mm}$ voxels, each associated with an intensity value representing the attenuation of the $X$-ray beams (Figure 4). Measurements from the merged $X$ ray scanning log reconstruction data were taken, utilizing the in-house algorithms of Finnos Ltd. The estimation of the basic density of the sapwood (ratio of dry weight to green volume) involved the analysis of the X-ray beam attenuation and predictive modelling with respect to device-specific calibration measurements. In general, the measured attenuation coefficient can be linearly linked with the density of the material (Fromm, 2001; Bucur, 2003). The system used in this study converted the estimated basic density $\left(\mathrm{kg} / \mathrm{m}^{3}\right)$ to an index value (I) by compressing the original range of values into a smaller range, but preserving the relative differences between values. Knot whorls were identified from the X-ray data, based on their higher attenuation value in comparison to the surrounding wood, utilizing a pattern-recognition adaptation of neural networks (Hagman, 1995; Oja et al., 2003; Longuetaud, 2005; Fredriksson, 2012) (Figure 4). Whorl location was measured as the height from the log bottom to the centre of the whorl. The locations were used to calculate the mean whorl-to-whorl distance in each log. For further reading, applications of X-ray scanning data in wood property measurements and identification of the varying structures in wood were reviewed by Wei et al. (2011).

\section{Statistical analysis}

The final values of the sawmill measurements, used as the reference data and referred to as sawmill data from here on, corresponded to the mean values of the two repetitions. The accuracy of the sawmill references was analysed by calculating a mean difference (MD) and $95 \%$ confidence interval $(\mathrm{Cl})$ between the repetitions and using a paired t-test to determine whether the differences were statistically significant $(p<0.05)$. Relative MDs were also calculated as the proportion of the MD to the sawmill measurement. 
Since this study focused only on a sample of trees instead of on an entire stand, we bucked the TLS tree models to logs, using the ID-numbered log lengths from the sawmill data. The exact stump height was unknown, but we assumed that the harvester had cut the first log just above the root collar. Log-specific over-bark top-end diameter, stem taper, sweep and volume were measured from the TLS-based stem models, applying the principles of the sawmill measurements (Figure 2), and compared with the reference. The comparisons were conducted separately for butt logs and other logs, i.e. the middle logs and top logs were bundled together, due to the small number (9) of top logs. Similarly, in the comparison of the sawmill measurement repetitions we used the MD, relative $\mathrm{MD}, 95 \% \mathrm{Cl}$ and paired t-test to determine the statistical significance of the differences between the TLS measurements and the sawmill reference. In addition, a correlation matrix of Pearson's correlation coefficients $(r)$ was calculated between all the variables and between the TLS and sawmill data for all the logs and the various log types separately. To assess the relationship between wood quality and the TLS-derived variables describing log geometry, we inspected $r$ between the log geometry variables, log-specific basic density and whorl-to-whorl mean distance values from the Xray scanning measurements.

\section{Results}

Statistical differences were found between the two sawmill measurement repetitions for top-end diameter and volume, but the relative MDs remained below 3\%. Statistical differences were also found for butt log taper (relative MD 5.8\%) and basic density values (relative MD 1.1\%). The descriptive statistics of the sawmill measurement repetitions, their MDs and the results of paired ttests are presented in Table 2.

The estimates of the log-specific top-end diameter and volume based on TLS stem models differed from the reference measurements in a statistically significant manner, having relative MDs of $1.6 \%$ and $-2.4 \%$, respectively, considering all log types together (Table 3). For all logs together, as well as for the various log types separately, the top-end diameter and volume estimates were highly correlated between the TLS tree models and sawmill measurements, with $r$ ranging between 0.88 and 0.99 (Table 4). Figure 5 shows that the TLS stem models tended to slightly overestimate the topend diameter, especially as the diameter increased, while the log volume estimates were generally close to unbiased, and not dependent on the size of the log.

The taper values of the TLS stem models showed a relative MD of $-3.0 \%$ in comparison to the sawmill references, considering all log types. However, the difference was not statistically significant (Table 3), and $r$ was more than 0.75 between estimates from sawmill measurements and TLS stem models for all log types together or separately (Table 4). The sweep estimates differed from the reference in a statistically significant manner, the relative MD showing a $78.13 \%$ difference between the data sets when all logs were considered and $r$ ranging from 0.47 to 0.62 when all logs were considered or different log types were considered separately (Table 4). Neither taper nor sweep estimates were clearly associated with the magnitude of the variable (Figure 5).

When we compared the log properties with the wood quality variables, the results showed negative correlations between the basic density and increasing top-end diameter, volume and tapering of logs (Table 4). The relationship between tapering and basic density in all logs together was more clear when the tapering value from the sawmill measurements was used $(r=-0.62)$. A negative 
correlation ( $r=-0.51$ ) was found between the TLS-based tapering and mean whorl-to-whorl distances when all logs were considered (Table 4). Figure 6 illustrates the results of the comparison in scatter plots. Clear associations were observed between basic density and top-end diameter (Figure 6a), volume (Figure 6c) and taper for middle and top logs (Figure 6e), and between the mean whorl-to-whorl distances and taper, especially in the middle and top logs (Figure 6f).

\section{Discussion}

Our analysis of the applicability of stem models based on high-density terrestrial point clouds in contributing to preharvest log breakdown optimization at sawmills used state-of-the-art sawmill data as references. Analysing the precision of the reference data is crucial to enabling proper interpretation of the comparison results. Paired t-tests of the sawmill measurement repetitions that made up the reference showed that statistically significant differences may exist between two measurement rounds. However, the relative MDs remained below $4 \%$ for all variables, which suggests high accuracy of the reference data and set the level for the TLS stem models.

Our results showed that TLS point cloud-based tree models tend to slightly overestimate the log diameters, especially for the butt logs (Table 3). Errors in diameter estimation propagate to the volume and taper estimates. In this study, the volume estimates for the top logs differed from the reference in a statistically significant manner, while the taper values were estimated as being nearly unbiased (Table 3). It is worth noting that the diameter measurement heights may have varied somewhat between the TLS and sawmill data, because the exact stump height was not known. The stem diameter estimates were also extrapolated between the measurement points by means of spline interpolation, in which the estimation of $\mathrm{H}$ and selection of the smoothing parameter may also have resulted in errors to the estimates (Figure 2). Nevertheless, the estimation errors were similar in magnitude to those between the two repetitive sawmill measurements (Tables 2 and 3 ). The remaining differences were generally below $1 \mathrm{~cm}$, and the accuracy of the stem dimensions estimation was thus higher than in most previous studies utilizing either cylinder or circle fitting (Henning and Radtke, 2006; Liang et al., 2012; Olofsson et al., 2014; Olofsson and Holmgren, 2016; Wang et al., 2016; de Conto et al., 2017; Koreň et al., 2017). This was probably due to the favourable scanning conditions (i.e. both understorey and wind were minimal) and a high scanning density (point-to-point distance $3.1 \mathrm{~mm}$ at $10 \mathrm{~m}$ ). Also a possible source of overestimation is that the area a laser beam illuminates when emitted onto a cylindrical object is elliptical rather than circular, and TLS point cloud-based cylinder models are therefore generally prone to slight overestimation, as reported by Forsman et al. (2018).

Sweep was largely overestimated in the TLS stem models. The result indicates that although the diameter estimates were in line with the references, the stem centre point estimation differs between the sawmill measurements and the TLS stem modelling. At the sawmill, the sweep was estimated from three directions, using a 2-D diagram of log centre points, and thus the orientation of the log on the measurement table affects the sweep measurement at the sawmill. In the TLS stem model, the centre point was estimated in 3-D as the centre of a cylinder fitted to the stem points. Our results thus pointed out an issue that should be paid more attention to in the future: the are possible with either method. Previous research on sweep estimation is sparse. Thies et al. (2004) 
demonstrated a sweep-estimation approach, but they had no references to show the accuracy of their approach.

The log geometry variables from both the sawmill measurements and TLS stem models resulted in logical correlations with the inspected wood quality variables, namely wood density and knottiness of the logs that were measured by means of X-ray scanning. Based on our results, the wood density decreased together with increasing log dimensions (Figure 6). Downes et al. (2002) argued that the relationship between rapid growth and decreased wood density is not necessarily causal per se, but rather a likely consequence of prolonged juvenile wood formation in trees that maintain long live crowns and exhibit rapid axial growth (Mansfield et al., 2007; Kuprevicius et al., 2013). The larger, dominant trees in this study may have comprised larger proportions of juvenile wood, similar to trees from widely spaced and fertile sites. Cortini et al. (2013) linked increasing site fertility with increasing growth ring area for four different conifers, and Benjamin et al. (2009) associated the increasing tree spacing with decreasing modulus of elasticity in black spruce (Picea mariana [Mill.] BSP). Furthermore, the sapwood basic density decreased with increasing tapering, especially in butt logs (Table 4, Figure 6e), which is in line with previous results, e.g. Lindström (1996) and Fabris (2000), who linked heavy stem tapering to rapid axial growth and lower wood density. Our results also showed that, especially in middle and top logs (Figure 6f), the tapering was negatively correlated with the mean whorl-to-whorl distances (Table 4), which was also observed in studies conducted by Björklund (1997) and Mäkinen (1999). Tapering was minimal in the middle logs and increased again in the top logs (Table 2, Figure 2). The knots found in the middle logs were likely grown under heavy competition, their life cycle and consequently the length of the live crown having been shorter and the growth resources allocated to growth in the stem apex, resulting in small taper value and long whorl-to-whorl distances. The knots within the top logs, in turn, were likely grown after the final thinning, when the trees have allocated their growth resources to rapid axial growth instead of growth in $\mathrm{H}$ and the whorl-to-whorl distances have remained shorter.

Since stem shape is closely associated with crown properties, similar estimates of log properties and wood quality could also have been estimated through crown geometry and individual branching parameters. For example, Blanchette et al. (2015) analysed stand-specific canopy structure and competition indicators measured from TLS point clouds and presented models for predicting several wood properties, including wood density and microfibril angles. In Pyörälä et al. (2017), manual branch measurements from TLS point clouds were compared with knots detected in X-ray scanning. The study concluded that approximately $55 \%$ of the whorls could be identified, with most of the discrepancy resulting from the bottom parts of the stem, where the branches had self-pruned. In addition, the increasing distance from the scanner results in diminishing point density in the upper parts of the tree crown and the terrestrial point clouds are not feasible for detecting individual branches deeper in the live crown. Therefore, it is reasonable to assume that both the stem taper data and branching data should be used in a complementary manner to comprehensively assess the wood quality of standing timber. Geometrical tree-modelling approaches to retrieve branching structures in addition to the stem have been demonstrated by Côté et al. (2012), Raumonen et al. (2013), Bournez et al. (2017) and Pyörälä et al. (2018). Further research should utilize these additional variables in the linking of standing timber properties to the wood quality variables from sawmill data. 
It is worth noting that our test data were small and entailed high-density point clouds that covered individual trees as completely as possible. When the area of interest increases, the spatial range of TLS tends to limit the coverage, resolution and quality of the data achievable (Abegg et al., 2017; Wilkes et al., 2017; Liang et al., 2018a). Alternatively, a laser-scanner can also be mounted on a moving platform (MLS, mobile laser scanning), which enables faster acquisition of point cloud data with resolution similar to that of TLS (Liang et al., 2018b). The data- processing time for TLS and MLS point clouds may yet be long, but future developments in algorithms and computing power are likely to reduce the processing time.

As an outlook, if sawmills gathered MLS data from the top of a harvester during harvesting operations and linked the standing timber's stem (and branching) geometry with sawmill data, the resulting database could be used to optimize the sawing and predict sawn wood product recoveries at potential harvest sites, using remote sensing. Barth et al. (2015) and Sanz et al. (2018) used aerial remote-sensing data, field references and harvester bucking data from previously harvested forest sites. They produced lists of trees with 2-D stem profiles based on the field and harvester data, then bucked the tree lists in a simulation and imputed the log product recovery estimations to their study stands, using the remote-sensing data. If the field references involved 3-D stem models and were linked with wood quality information, simulated sawn wood product recoveries could be estimated at potential harvest sites and used to optimize the log breakdown prior to the harvest.

\section{Conclusion}

The results of the current study showed that stem diameters along the length of the sawlog section can be estimated with similar accuracy to that at the sawmill, using high-density terrestrial point clouds scanned under favourable conditions. The results thus imply that stem-model dimensions resolved from point clouds could be used to link sawmill wood quality data with standing timber. However, the proposed approach may not yet be fully feasible, due to the non-uniform definition of sweep, and although logical relationships exist between the stem-model geometry and wood quality, the correlations in this study remained moderate at best. In further studies, the additional information obtainable from the point clouds should be included to further explore the possible advantages that the 3-D point cloud data provide for wood procurement planning. Moreover, in an operational setting, mobile platforms are probably better suited for data acquisition than the static TLS.

\section{Funding}

This work was supported by financial aid received from the Finnish Academy project 'Centre of Excellence in Laser Scanning Research (CoE-LaSR) [272195]', Ministry of Agriculture and Forestry of Finland project 'Puuston laatutunnukset' [OH300-S42100-03], Foundation for Research of Natural Resources in Finland [1780/15, 1790/16 and 1798/17], Finnish Forest Foundation [2014092904], and Jenny ja Antti Wihurin rahasto.

\section{Acknowledgements}

The authors would like to acknowledge Dr Antti Uotila from the Hyytiälä Forest Station (University of Helsinki) for arranging the harvesting of the forest stand examined. Antti Raatevaara (University of Helsinki, currently at the Institute of Natural Resources Finland) is acknowledged for marking the 
sample trees during the harvest and coordinating the measurements of sample logs at the sawmill. Ari Toivonen, Sami Kotivuori and Jukka Mäkinen from 'Korkeakosken saha' - sawmill (UPM-Kymmene Oyj) are acknowledged for providing the sawmill data, with special thanks to Ari Toivonen for advice and information on the sawing process and sawmill practices. Juha Alatalo (Finnos Ltd.) is acknowledged for providing the X-ray data for our use and information on the equipment and measurements. The language was edited by Dr James Thompson.

\section{Conflict of interest statement}

None declared.

\section{References}

Abegg, M., Kükenbrink, D., Zell, J., Schaepman, M.E. and Morsdorf, F. 2017 Terrestrial Laser Scanning for Forest Inventories-Tree Diameter Distribution and Scanner Location Impact on Occlusion. Forests, 8 (6), 184.

Auty, D., Achim, A., Bédard, P. and Pothier, D. 2014 StatSAW: modelling lumber product assortment using zero-inflated Poisson regression. Canadian Journal of Forest Research, 44 (6), 638-647.

Barth, A., Möller, J.J., Wilhelmsson, L., Arlinger, J., Hedberg, R. and Söderman, U. 2015 A Swedish case study on the prediction of detailed product recovery from individual stem profiles based on airborne laser scanning. Ann Forest Sci, 72 (1), 47-56.

Benjamin, J.G., Kershaw, J., John A, Weiskittel, A.R., Chui, Y.H. and Zhang, S. 2009 External knot size and frequency in black spruce trees from an initial spacing trial in Thunder Bay, Ontario. The Forestry Chronicle, 85 (4), 618-624.

Björklund, L. 1997 The interior knot structure of Pinus sylvestris stems. Scand J Forest Res, 12 (4), 403-412.

Blanchette, D., Fournier, R.A., Luther, J.E. and Côté, J.-F. 2015 Predicting wood fiber attributes using local-scale metrics from terrestrial LiDAR data: A case study of Newfoundland conifer species. Forest Ecol Manag, 347, 116-129.

Bournez, E., Landes, T., Saudreau, M., Kastendeuch, P. and Najjar, G. 2017 From TLS point clouds to 3D models of trees: a comparison of existing algorithms for 3D tree reconstruction. ISPRSInternational Archives of the Photogrammetry, Remote Sensing and Spatial Information Sciences, 42 (2), 113-120.

Bucur, V. 2003 lonizing radiation computed tomography. In Nondestructive Characterization and Imaging of Wood, Springer, pp. 13-73.

Burdon, R.D., Kibblewhite, R.P., Walker, J.C., Megraw, R.A., Evans, R. and Cown, D.J. 2004 Juvenile versus mature wood: a new concept, orthogonal to corewood versus outerwood, with special reference to Pinus radiata and P. taeda. Forest Sci, 50 (4), 399-415.

Cortini, F., Groot, A. and Filipescu, C.N. 2013 Models of the longitudinal distribution of ring area as a function of tree and stand attributes for four major Canadian conifers. Ann Forest Sci, 70 (6), 637-648.

Côté, J.-F., Fournier, R.A., Frazer, G.W. and Niemann, K.O. 2012 A fine-scale architectural model of trees to enhance LiDAR-derived measurements of forest canopy structure. Agricultural and Forest Meteorology, 166 (1), 72-85.

de Conto, T., Olofsson, K., Görgens, E.B., Rodriguez, L.C.E. and Almeida, G. 2017 Performance of stem denoising and stem modelling algorithms on single tree point clouds from terrestrial laser scanning. Computers and Electronics in Agriculture, 143, 165-176.

Downes, G.M., Wimmer, R. and Evans, R. 2002 Understanding wood formation: gains to commercial forestry through tree-ring research. Dendrochronologia, 20 (1-2), 37-51.

Fabris, S.p. 2000 Influence of cambial ageing, initial spacing, stem taper and growth rate on the wood quality of three coastal conifers, University of British Columbia. 
Forsman, M., Börlin, N., Olofsson, K., Reese, H. and Holmgren, J. 2018 Bias of cylinder diameter estimation from ground-based laser scanners with different beam widths: A simulation study. Isprs J Photogramm, 135, 84-92.

Fredriksson, M. 2012 Reconstruction of Pinus Sylvestris knots using measurable log features in the Swedish Pine Stem Bank. Scand J Forest Res, 27 (5), 481-491.

Fredriksson, M. 2014 Log sawing position optimization using computed tomography scanning. Wood Material Science \& Engineering, 9 (2), 110-119.

Fromm, J.H. 2001 Xylem Water Content and Wood Density in Spruce and Oak Trees Detected by High-Resolution Computed Tomography. Plant physiology (Bethesda), 127 (2), 416-425.

Hackenberg, J., Morhart, C., Sheppard, J., Spiecker, H. and Disney, M. 2014 Highly Accurate Tree Models Derived from Terrestrial Laser Scan Data: A Method Description. Forests, 5 (5), 10691105.

Hagman, P.O.G. 1995 Classification of scots pine (Pinus sylvestris) knots in density images from CT scanned logs Klassifizieren von Ästen in Kiefern-Rundholz anhand von Dichtebestimmungen durch Computer-Tomographie (CT). Holz als Roh- und Werkstoff, 53 (1), 75-81.

Henning, J.G. and Radtke, P.J. 2006 Detailed stem measurements of standing trees from groundbased scanning lidar. Forest Sci, 52 (1), 67-80.

Huuskonen, S., Hakala, S., Mäkinen, H., Hynynen, J. and Varmola, M. 2014 Factors influencing the branchiness of young Scots pine trees. Forestry, 87 (2), 257-265.

Kankare, V., Vauhkonen, J., Tanhuanpää, T., Holopainen, M., Vastaranta, M., Joensuu, M. et al. 2014 Accuracy in estimation of timber assortments and stem distribution-A comparison of airborne and terrestrial laser scanning techniques. Isprs J Photogramm, 97, 89-97.

Kivinen, V.P. and Uusitalo, J. 2002 Applying fuzzy logic to tree bucking control. Forest Sci, 48 (4), 673684.

Koreň, M., Mokroš, M. and Bucha, T. 2017 Accuracy of tree diameter estimation from terrestrial laser scanning by circle-fitting methods. International Journal of Applied Earth Observation and Geoinformation, 63, 122-128.

Kuprevicius, A., Auty, D., Achim, A. and Caspersen, J.P. 2013 Quantifying the influence of live crown ratio on the mechanical properties of clear wood. Forestry, 86 (3), 361-369.

Liang, X., Hyyppä, J., Kaartinen, H., Lehtomäki, M., Pyörälä, J., Pfeifer, N. et al. 2018a International benchmarking of terrestrial laser scanning approaches for forest inventories. Isprs J Photogramm, 144, 137-179.

Liang, X., Kankare, V., Hyyppä, J., Wang, Y., Kukko, A., Haggrén, H. et al. 2016 Terrestrial laser scanning in forest inventories. Isprs J Photogramm, 115 (1), 63-77.

Liang, X., Kukko, A., Hyyppä, J., Lehtomäki, M., Pyörälä, J., Yu, X. et al. 2018b In-situ measurements from mobile platforms: An emerging approach to address the old challenges associated with forest inventories. Isprs J Photogramm, 143 (1), 97-107.

Liang, X., Wang, Y., Jaakkola, A., Kukko, A., Kaartinen, H., Hyyppä, J. et al. 2015 Forest data collection using terrestrial image-based point clouds from a handheld camera compared to terrestrial and personal laser scanning. leee T Geosci Remote, 53 (9), 5117-5132.

Liang, X.L., Kankare, V., Yu, X.W., Hyyppä, J. and Holopainen, M. 2014 Automated Stem Curve Measurement Using Terrestrial Laser Scanning. leee T Geosci Remote, 52 (3), 1739-1748.

Liang, X.L., Litkey, P., Hyyppä, J., Kaartinen, H., Vastaranta, M. and Holopainen, M. 2012 Automatic Stem Mapping Using Single-Scan Terrestrial Laser Scanning. leee T Geosci Remote, 50 (2), 661-670.

Lindström, H. 1996 Basic density of Norway spruce. Part II. Predicted by stem taper, mean growth ring width, and factors related to crown development. Wood Fiber Sci, 28 (2), 240-251.

Longuetaud, F. 2005 Automatic Detection of Annual Growth Units on Picea abies Logs Using Optical and X-Ray Techniques. Journal of nondestructive evaluation, 24 (1), 29-43.

Lundgren, C. 2000 Predicting log type and knot size category using external log shape data from a 3D log scanner. Scand J Forest Res, 15 (1), 119-126. 
Maas, H.G., Bienert, A., Scheller, S. and Keane, E. 2008 Automatic forest inventory parameter determination from terrestrial laser scanner data. Int J Remote Sens, 29 (5), 1579-1593.

Mäkelä, A., Grace, J., Deckmyn, G., Kantola, A. and Kint, V. 2010 Simulating wood quality in forest management models. Forest systems, 19, 48-68.

Mäkinen, H. 1999 Growth, suppression, death, and self-pruning of branches of Scots pine in southern and central Finland. Can J Forest Res, 29 (5), 585-594.

Mansfield, S.D., Parish, R., Goudie, J.W., Kang, K.-Y. and Ott, P. 2007 The effects of crown ratio on the transition from juvenile to mature wood production in lodgepole pine in western Canada. Canadian journal of forest research, 37 (8), 1450-1459.

Mengesha, T., Hawkins, M. and Nieuwenhuis, M. 2015 Validation of terrestrial laser scanning data using conventional forest inventory methods. Eur J Forest Res, 134 (2), 211-222.

Murphy, G.E., Acuna, M.A. and Dumbrell, I. 2010 Tree value and log product yield determination in radiata pine (Pinus radiata) plantations in Australia: comparisons of terrestrial laser scanning with a forest inventory system and manual measurements. Canadian journal of forest research, 40 (11), 2223-2233.

Nordmark, U. 2005 Value recovery and production control in bucking, log sorting, and log breakdown. Forest Prod J, 55 (6), 73.

Nordmark, U. and Oja, J. 2004 Prediction of board values in Pinus sylvestris sawlogs using x-ray scanning and optical three-dimensional scanning of stems. Scand J Forest Res, 19 (5), 473480.

Oja, J., Grundberg, S., Fredriksson, J. and Berg, P. 2004 Automatic grading of sawlogs: A comparison between X-ray scanning, optical three-dimensional scanning and combinations of both methods. Scand J Forest Res, 19 (1), 89-95.

Oja, J., Wallbäcks, L., Grundberg, S., Hägerdal, E. and Grönlund, A. 2003 Automatic grading of Scots pine (Pinus sylvestris L.) sawlogs using an industrial X-ray log scanner. Computers and electronics in agriculture, 41 (1), 63-75.

Ojansuu, R., Mäkinen, H. and Heinonen, J. 2018 Including variation in branch and tree properties improves timber grade estimates in Scots pine stands. Canadian Journal of Forest Research, 48 (999), 1-12.

Olofsson, K. and Holmgren, J. 2016 Single tree stem profile detection using terrestrial laser scanner data, flatness saliency features and curvature properties. Forests, 7 (9), 207.

Olofsson, K., Holmgren, J. and Olsson, H. 2014 Tree stem and height measurements using terrestrial laser scanning and the ransac algorithm. Remote Sens-Basel, 6 (5), 4323-4344.

Pinto, I., Knapic, S., Pereira, H. and Usenius, A. 2006 Simulated and realised industrial yields in sawing of maritime pine (Pinus pinaster Ait.). Holz Roh Werkst, 64 (1), 30-36.

Pyörälä, J., Kankare, V., Vastaranta, M., Rikala, J., Holopainen, M., Sipi, M. et al. 2017 Comparison of terrestrial laser scanning and X-ray scanning in measuring Scots pine (Pinus sylvestris L.) branch structure. Scandinavian Journal of Forest Research, 33 (3), 291-298.

Pyörälä, J., Liang, X., Vastaranta, M., Saarinen, N., Kankare, V., Wang, Y. et al. 2018 Quantitative assessment of Scots pine (Pinus sylvestris L.) whorl structure in a forest environment using terrestrial laser scanning. IEEE Journal of Selected Topics in Applied Earth Observations and Remote Sensing, 11 (10), 3598-3607.

R, C.T. 2018 R: A Language and Environment for Statistical Computing. 3.5.0 Ed., R Foundation for Statistical Computing, Vienna, Austria.

Raumonen, P., Kaasalainen, M., Akerblom, M., Kaasalainen, S., Kaartinen, H., Vastaranta, M. et al. 2013 Fast Automatic Precision Tree Models from Terrestrial Laser Scanner Data. Remote Sens-Basel, 5 (2), 491-520.

Rune, G. and Warensjö, M. 2002 Basal sweep and compression wood in young Scots pine trees. Scand J Forest Res, 17 (6), 529-537. 
Saarinen, N., Kankare, V., Vastaranta, M., Luoma, V., Pyörälä, J., Tanhuanpää, T. et al. 2017 Feasibility of Terrestrial laser scanning for collecting stem volume information from single trees. Isprs J Photogramm, 123, 140-158.

Sanz, B., Malinen, J., Leppänen, V., Valbuena, R., Kauranne, T. and Tokola, T. 2018 Valuation of growing stock using multisource GIS data, a stem quality database, and bucking simulation. Canadian Journal of Forest Research, 48 (8), 888-897.

Stängle, S.M., Bruchert, F., Kretschmer, U., Spiecker, H. and Sauter, U.H. 2014 Clear wood content in standing trees predicted from branch scar measurements with terrestrial LiDAR and verified with X-ray computed tomography. Can J Forest Res, 44 (2), 145-153.

Taylor, F.W. and Wagner, F.G. 1996 Impact of log sweep on warp in Douglas-fir structural lumber. Forest Prod J, 46 (9), 53.

Thies, M., Pfeifer, N., Winterhalder, D. and Gorte, B.G. 2004 Three-dimensional reconstruction of stems for assessment of taper, sweep and lean based on laser scanning of standing trees. Scand J Forest Res, 19 (6), 571-581.

Todoroki, C. 1990 AUTOSAW system for sawing simulation. Nz J Forestry Sci, 20 (3), 332-348.

Van Leeuwen, M., Hilker, T., Coops, N.C., Frazer, G., Wulder, M.A., Newnham, G.J. et al. 2011 Assessment of standing wood and fiber quality using ground and airborne laser scanning: $A$ review. Forest Ecol Manag, 261 (9), 1467-1478.

Wallace, L., Lucieer, A., Watson, C. and Turner, D. 2012 Development of a UAV-LiDAR system with application to forest inventory. Remote Sens-Basel, 4 (6), 1519-1543.

Wang, D., Hollaus, M., Puttonen, E. and Pfeifer, N. 2016 Automatic and self-adaptive stem reconstruction in landslide-affected forests. Remote Sens-Basel, 8 (12), 974.

Wei, Q., Leblon, B. and La Rocque, A. 2011 On the use of X-ray computed tomography for determining wood properties: a review. Canadian journal of forest research, 41 (11), 21202140.

Wilkes, P., Lau, A., Disney, M., Calders, K., Burt, A., de Tanago, J.G. et al. 2017 Data acquisition considerations for Terrestrial Laser Scanning of forest plots. Remote Sens Environ, 196 (1), 140-153.

Xia, S., Wang, C., Pan, F., Xi, X., Zeng, H. and Liu, H. 2015 Detecting stems in dense and homogeneous forest using single-scan TLS. Forests, 6 (11), 3923-3945.

Yerbury, M. and Cooper, R. 2010 Curve sawing spruce sawlogs containing sweep can reduce drying distortion when compared with conventional sawing. Forestry, 83 (4), 443-450.

Table 1. Study site description based on stand-wise forest inventory from year 2015. G = basal area, $\mathrm{D}_{\mathrm{gm}}=$ basal area-weighted mean diameter, $\mathrm{H}_{\mathrm{gm}}=$ basal area-weighted mean height, and $\mathrm{V}=$ total stem volume per hectare.

$\begin{array}{ll}\text { Regeneration } & \text { Sow } \\ \text { Established (year) } & 1950 \\ \text { Thinnings (year) } & 1983,1999 \\ \text { Site type } & \text { Sub-xeric } \\ \text { Vegetation type } & \text { Vaccinium } \\ \text { Area (ha) } & 1.7 \\ \text { Stems (No./ha) } & 617 \\ \mathrm{G}\left(\mathrm{m}^{2} / \mathrm{ha}\right) & 28.0 \\ \mathrm{D}_{\mathrm{gm}}(\mathrm{cm}) & 25.0 \\ \mathrm{H}_{\mathrm{gm}}(\mathrm{m}) & 21.0 \\ \mathrm{~V}\left(\mathrm{~m}^{3} / \mathrm{ha}\right) & 281.0\end{array}$


Table 2. Minimum, mean, maximum and standard deviation (SD) values of two repetitions of the sawmill measurements (Sawmill 1 and 2), and the log-specific differences and results of a paired ttest: mean difference (MD) with absolute and relative values, $95 \%$ confidence interval $(95 \% \mathrm{Cl})$, degrees of freedom ( $d f$ ) defined as $\mathrm{N}-1$ where $\mathrm{N}$ is the number of logs, the $t$-statistic $(t)$ and the statistical significance $(p)$ between the repetitions for all logs and different log types. The data included 52 butt logs, 42 middle logs and 9 top logs. Statistically significant differences $(p<0.05)$ are marked with an asterisk $(*)$.

\begin{tabular}{|c|c|c|c|c|c|c|c|c|c|c|c|c|c|}
\hline & \multicolumn{4}{|c|}{ Sawmill 1} & \multicolumn{4}{|c|}{ Sawmill 2} & \multicolumn{5}{|l|}{ Accuracy } \\
\hline & Min & $\operatorname{Max}$ & Mean & $S D$ & $\operatorname{Min}$ & $\operatorname{Max}$ & Mean & $S D$ & $M D(\%)$ & $95 \% \mathrm{Cl}$ & $d f$ & $t$ & $p$ \\
\hline Length (m) & 3.78 & 5.57 & 4.77 & 0.48 & 3.78 & 5.56 & 4.77 & 0.48 & $0.00(0.00)$ & $0.00-0.00$ & 102 & 0.57 & 0.57 \\
\hline Butt logs & 3.78 & 5.57 & 4.87 & 0.49 & 3.78 & 5.56 & 4.87 & 0.49 & $0.00(0.00)$ & $0.00-0.00$ & 51 & 0.75 & 0.45 \\
\hline Middle logs & 4.01 & 5.48 & 4.72 & 0.48 & 4.02 & 5.48 & 4.72 & 0.48 & $0.00(0.00)$ & $0.00-0.00$ & 41 & -0.11 & 0.91 \\
\hline Top logs & 4.26 & 4.89 & 4.48 & 0.26 & 4.26 & 4.90 & 4.48 & 0.26 & $0.00(0.00)$ & $0.00-0.01$ & 8 & 0.37 & 0.72 \\
\hline Top-end diameter $(\mathrm{cm})$ & ) 14.10 & 27.10 & 18.98 & 2.93 & 13.70 & 25.70 & 18.72 & 2.87 & $0.26(1.38)$ & $0.18-0.34$ & 102 & 6.48 & $<0.01 *$ \\
\hline Butt logs & 14.10 & 27.10 & 20.15 & 3.03 & 13.70 & 25.70 & 19.83 & 2.96 & $0.32(1.60)$ & $0.20-0.44$ & 51 & 5.46 & $<0.01^{*}$ \\
\hline Middle logs & 14.80 & 23.20 & 18.18 & 2.28 & 14.60 & 23.50 & 17.97 & 2.33 & $0.21(1.16)$ & $0.09-0.32$ & 41 & 3.59 & $<0.01^{*}$ \\
\hline Top logs & 14.90 & 18.60 & 15.94 & 1.14 & 14.70 & 18.00 & 15.82 & 1.11 & $0.12(0.76)$ & $-0.17-0.42$ & 8 & 0.96 & 0.37 \\
\hline Volume $\left(\mathrm{dm}^{3}\right)$ & 68.00 & 335.00 & 167.80 & 57.14 & 64.00 & 347.00 & 163.67 & 56.26 & $4.13(2.49)$ & $3.41-4.85$ & 102 & 11.36 & $<0.01^{*}$ \\
\hline Butt logs & 68.00 & 335.00 & 193.60 & 62.97 & 764.00 & 347.00 & 187.5 & 462.62 & $5.65(2.96)$ & $4.41-6.90$ & 51 & 9.12 & $<0.01 *$ \\
\hline Middle logs & 91.00 & 242.00 & 145.81 & 35.81 & 188.00 & 239.00 & 143.19 & 35.82 & $2.62(1.81)$ & $2.12-3.12$ & 41 & 10.66 & $<0.01^{*}$ \\
\hline Top logs & 106.00 & 169.00 & 121.33 & 322.12 & 2101.00 & 166.00 & 119.00 & 22.53 & $2.33(1.94)$ & $1.25-3.42$ & 8 & 4.95 & $<0.01^{*}$ \\
\hline Taper $(\mathrm{mm} / \mathrm{m})$ & 3.10 & 16.50 & 8.13 & 2.39 & 2.60 & 14.10 & 7.98 & 2.31 & $0.15(1.86)$ & $-0.06-0.36$ & 102 & 1.42 & 0.16 \\
\hline Butt logs & 4.60 & 16.50 & 8.23 & 2.39 & 2.60 & 14.10 & 7.77 & 2.31 & $0.46(5.75)$ & $0.15-0.77$ & 51 & 2.98 & $<0.01 *$ \\
\hline Middle logs & 3.10 & 10.00 & 7.23 & 1.52 & 2.90 & 10.90 & 7.46 & 1.61 & $-0.23(-3.13)$ & $-0.55-0.09$ & 41 & -1.45 & 0.16 \\
\hline Top logs & 7.90 & 14.80 & 11.72 & 2.30 & 7.60 & 13.70 & 11.57 & 2.09 & $0.16(1.37)$ & $-0.23-0.54$ & 8 & 0.92 & 0.38 \\
\hline Sweep $(\mathrm{mm} / \mathrm{m})$ & 1.30 & 13.00 & 4.53 & 2.30 & 1.10 & 12.50 & 4.43 & 2.20 & $0.10(2.23)$ & $-0.01-0.21$ & 102 & 1.74 & 0.08 \\
\hline Butt logs & 1.60 & 13.00 & 5.38 & 2.59 & 1.90 & 12.50 & 5.20 & 2.55 & $0.18(3.40)$ & $0.02-0.33$ & 51 & 2.28 & 0.03 \\
\hline Middle logs & 1.30 & 8.20 & 3.79 & 1.60 & 1.10 & 7.80 & 3.70 & 1.48 & $0.08(2.14)$ & $-0.1-0.26$ & 41 & 0.94 & 0.35 \\
\hline Top logs & 1.40 & 5.80 & 3.07 & 1.40 & 2.30 & 5.10 & 3.36 & 1.02 & $-0.29(-9.02)$ & $-0.66-0.09$ & 8 & -1.77 & 0.11 \\
\hline Basic density (I) & 114.00 & 135.00 & 125.9 & 35.14 & 115.00 & 135.0 & 126.8 & 74.69 & $-0.89(-0.70)$ & $-1.17--0.61$ & 102 & -6.32 & $<0.01 *$ \\
\hline Butt logs & 114.00 & 131.00 & 122.6 & 4.57 & 115.00 & 132.00 & 124.04 & 4.31 & $-1.37(-1.11)$ & $-1.77--0.96$ & 51 & -6.7 & $<0.01^{*}$ \\
\hline Middle logs & 121.00 & 135.00 & 129.19 & 3.16 & 120.00 & 135.00 & 129.67 & 72.97 & $-0.48(-0.37)$ & $-0.86--0.09$ & 41 & -2.5 & 0.02 \\
\hline Top logs & 125.00 & 135.00 & 130.11 & 2.76 & 124.00 & 134.00 & 130.22 & 23.27 & $-0.11(-0.08)$ & $-1.09-0.86$ & 8 & -0.26 & 0.8 \\
\hline Whorl-to-whorl (m) & 0.15 & 0.47 & 0.27 & 0.07 & 0.14 & 0.46 & 0.28 & 0.08 & $0.01(3.64)$ & $-0.65-0.09$ & 102 & -1.52 & 0.13 \\
\hline Butt logs & 0.15 & 0.28 & 0.22 & 0.03 & 0.14 & 0.29 & 0.22 & 0.04 & $0.00(0.00)$ & $-0.27-0.46$ & 51 & 0.52 & 0.61 \\
\hline Middle logs & 0.25 & 0.47 & 0.34 & 0.05 & 0.26 & 0.46 & 0.35 & 0.05 & $0.01(2.90)$ & $-1.43-0.07$ & 41 & -1.84 & 0.07 \\
\hline Top logs & 0.24 & 0.35 & 0.28 & 0.04 & 0.25 & 0.34 & 0.29 & 0.03 & 0.01 (3.51) & $-1.96-0.74$ & 8 & -1.05 & 0.33 \\
\hline
\end{tabular}

Table 3. Log-specific minimum, mean, maximum and standard deviation (SD) values of the measured variables for sawmill and terrestrial laser-scanning (TLS) data as well as the results of the paired ttest: mean difference (MD) in both absolute and relative terms, $95 \%$ confidence interval $(95 \% \mathrm{Cl})$, degrees of freedom (df) defined as $\mathrm{N}-1$ where $\mathrm{N}$ is the number of logs, $t$ the $\mathrm{t}$-statistic and $p$ the statistical significance. A positive MD indicates that TLS resulted in overestimation of the value, and vice versa. Statistically significant differences $(p<0.05)$ are marked with an asterisk $\left({ }^{*}\right)$.

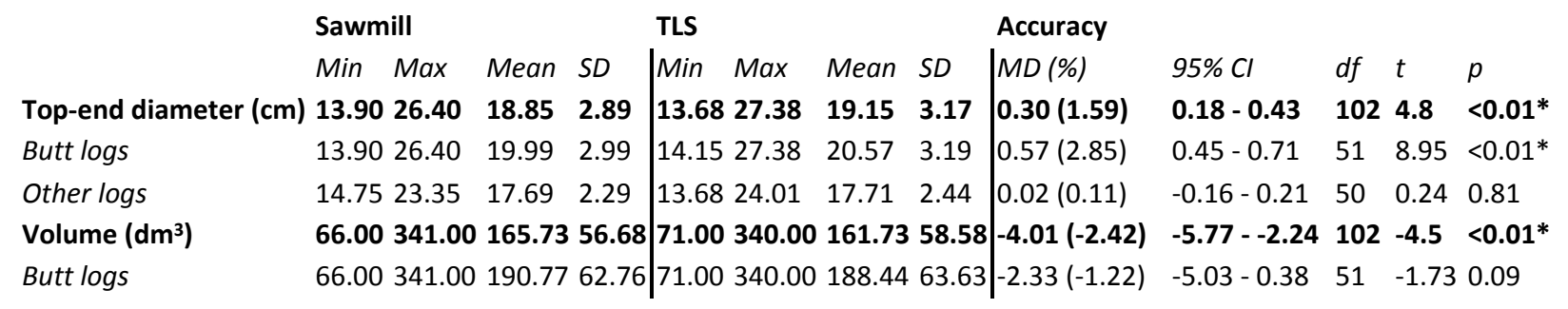


Other logs

Taper $(\mathrm{mm} / \mathrm{m})$

Butt logs

Other logs

Sweep $(\mathrm{mm} / \mathrm{m})$

Butt logs

Other logs
$89.50240 .50140 .2134 .91|81.00248 .00134 .4937 .03|-5.72(-4.08) \quad-7.97--3.4650 \quad-5.09<0.01 *$

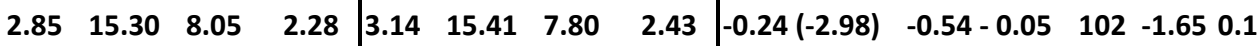

\begin{tabular}{llll|lllll|llllll}
3.60 & 15.30 & 8.00 & 2.29 & 3.14 & 15.41 & 7.69 & 2.70 & $-0.31(-3.88)$ & $-0.82-0.19$ & 51 & -1.24 & 0.22
\end{tabular}

\begin{tabular}{llll|lllll|llllll}
2.85 & 14.25 & 8.10 & 2.30 & 4.77 & 13.81 & 7.92 & 2.14 & $-0.18(-2.22)$ & $-0.51-0.15$ & 50 & -1.12 & 0.27
\end{tabular}

\begin{tabular}{llll|llll|llllll}
1.20 & 12.75 & 4.48 & 2.23 & 1.01 & 27.32 & 7.98 & 4.93 & $3.50(78.13)$ & $2.65-4.35$ & 102 & 8.16 & $<0.01 *$
\end{tabular}

\begin{tabular}{llll|lllll|lllll}
1.75 & 12.75 & 5.29 & 2.55 & 1.31 & 26.57 & 7.42 & 4.71 & $2.13(40.26)$ & $1.04-3.22$ & 51 & $3.93<0.01 *$
\end{tabular}

\begin{tabular}{llll|lllll|lllllll}
1.20 & 8.00 & 3.65 & 1.47 & 1.01 & 27.32 & 8.54 & 5.13 & $4.89(133.97)$ & $3.67-6.12$ & 50 & $7.99<0.01 *$
\end{tabular}
560

561

562

563

Table 4. Correlations ( $r$ ) between the terrestrial laser-scanning (TLS)-derived stem-model attributes and X-ray-derived basic densities and whorl-to-whorl distances in various log types and in all logs (boldface). The grey values indicate the absolute magnitude of the correlation.

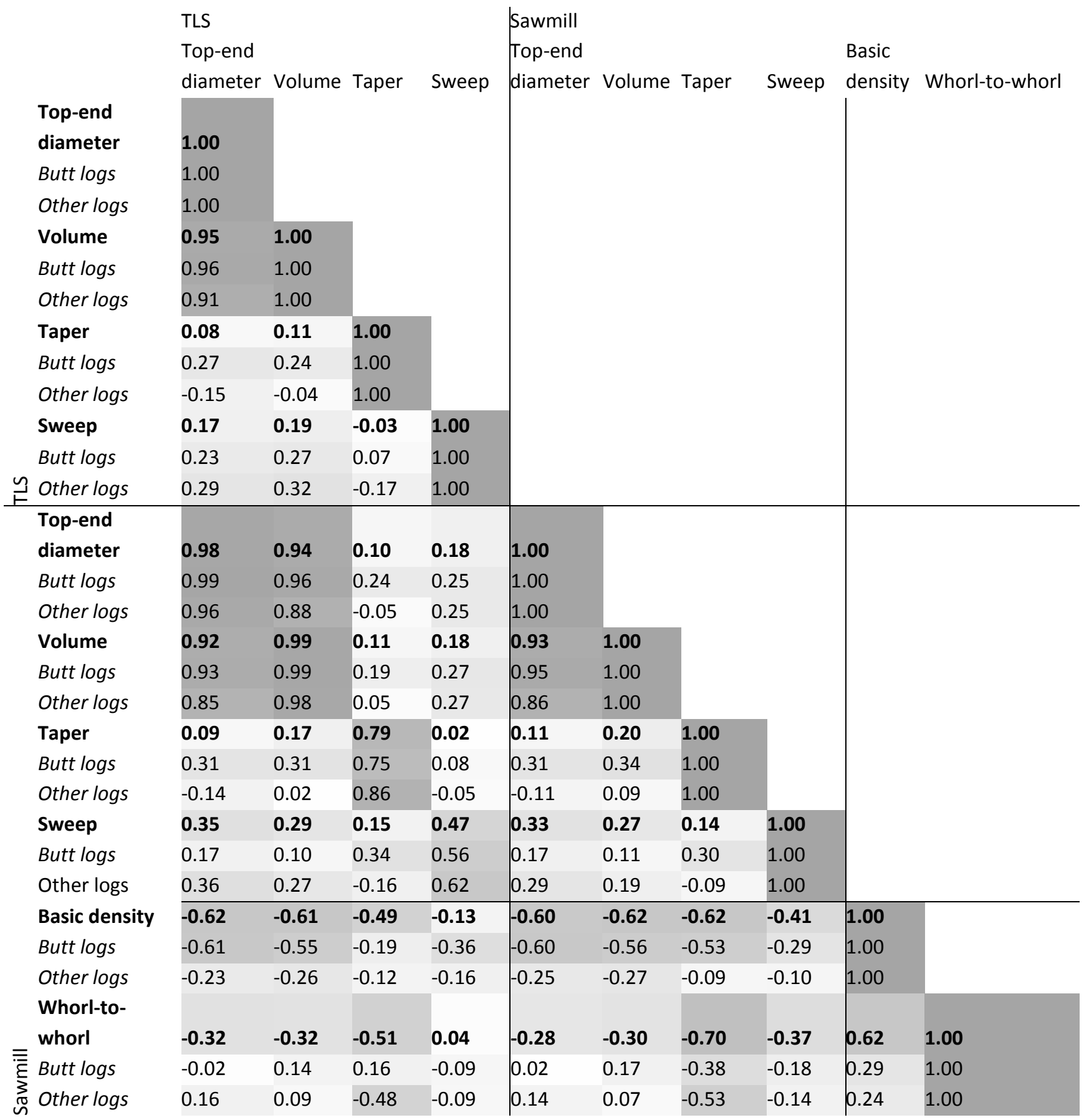




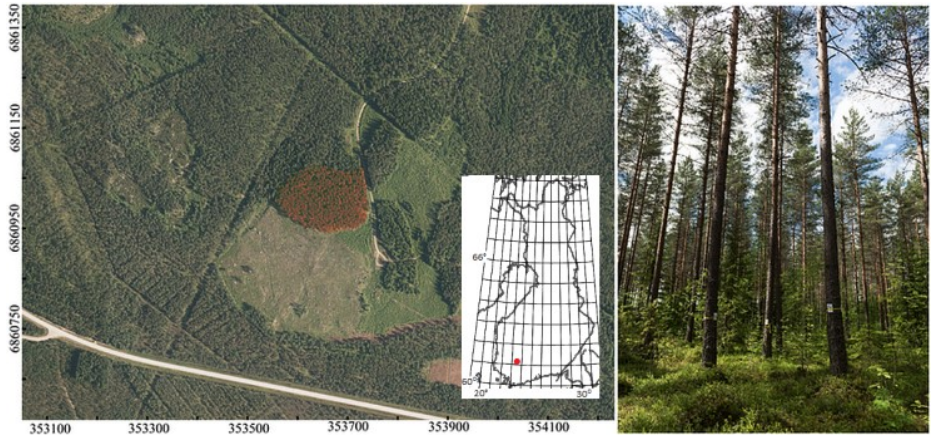

Figure 1. Left: The stand examined is highlighted in red in the aerial imagery (by the National Land location. Right: A photograph of the stand showing a group of three sample trees marked with identification numbers.

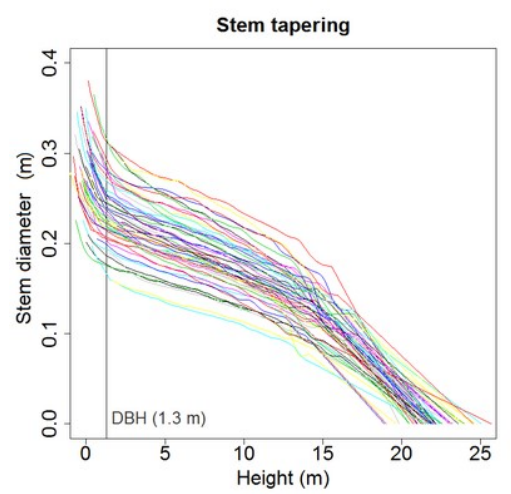

569

Figure 2. Sample tree stem curves (52). The stem diameter at a given height corresponds to the result of the cubic spline smoothing of the diameters of the cylinders fitted to the stem point clouds.
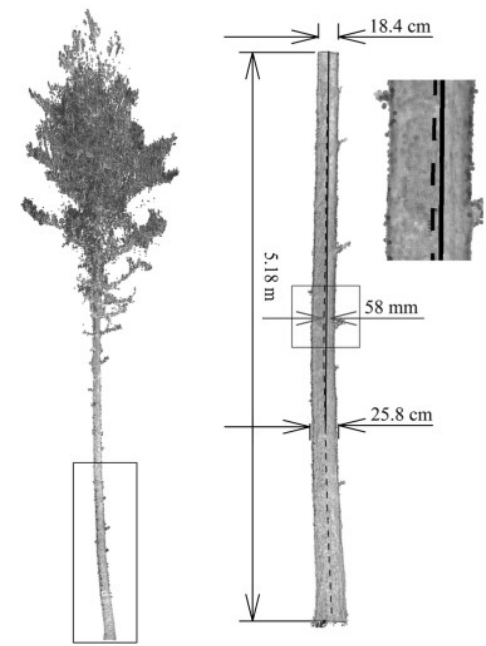

Figure 3. Illustration of the log geometry metrics used in this study, overlaid on a terrestrial laserscanning point cloud of a butt log. The log length $(5.18 \mathrm{~m})$ is given by the vertical arrow on the lefthand side. The log top-end diameter $(18.4 \mathrm{~cm})$ and diameter at $2 / 3$ length from the top-end $(25.8$ $\mathrm{cm})$ are indicated with horizontal arrows above and below the log, respectively. The log taper (14.3 
$\mathrm{mm} / \mathrm{m}$ ) is calculated as the difference of the two diameters, divided by the length of the log. The horizontal arrows in the middle give the maximum deviation between the log centre line (dashed) and the direct line (solid) from the top-end down a $2 / 3$ length of the log $(58 \mathrm{~mm}$ ); sweep (11.2 $\mathrm{mm} / \mathrm{m}$ ) is calculated from this value by dividing it with the full length of the log.

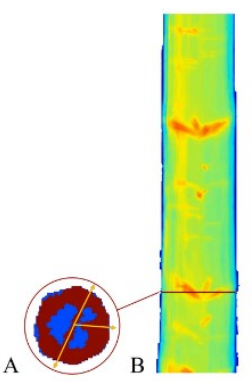

Figure 4. A general example of log reconstruction from four-directional X-ray scanning. In crosssectional images as shown in A), heartwood (blue) is separated from knots and sapwood (red). The arrows in the cross-section give the knot directions. The log data as shown in B) are reconstructed longitudinally by merging consecutive cross-sectional images. The attenuation of the $\mathrm{X}$-ray beams is used to interpret different structures in the log. (B): Knot whorls (red) are identified from the image, based on their higher density in comparison to the surrounding heartwood (yellow-green), and the basic density of the sapwood (cyan) is interpreted from the attenuation values with respect to the device-specific calibration measurements. The bark is illustrated in blue. The red horizontal line indicates the location of the cross-sectional image (A). The figure is by courtesy of Finnos Ltd., and the log is not from this study.

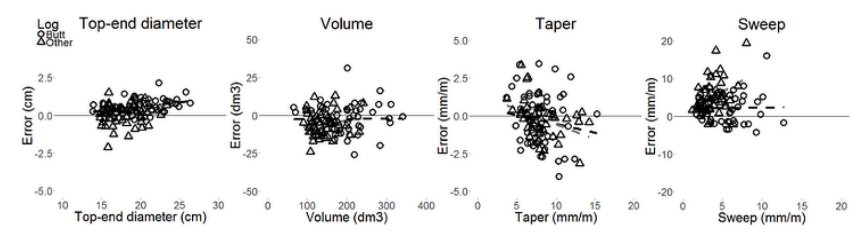

Figure 5. Scatter plots representing the differences between the terrestrial laser-scanning (TLS) point cloud measurements and the sawmill measurements with respect to the magnitude of the Inspected variable. A positive error indicates that TLS resulted in overestimation of the value, and vice versa. The number of butt logs is 52 and other logs 51.

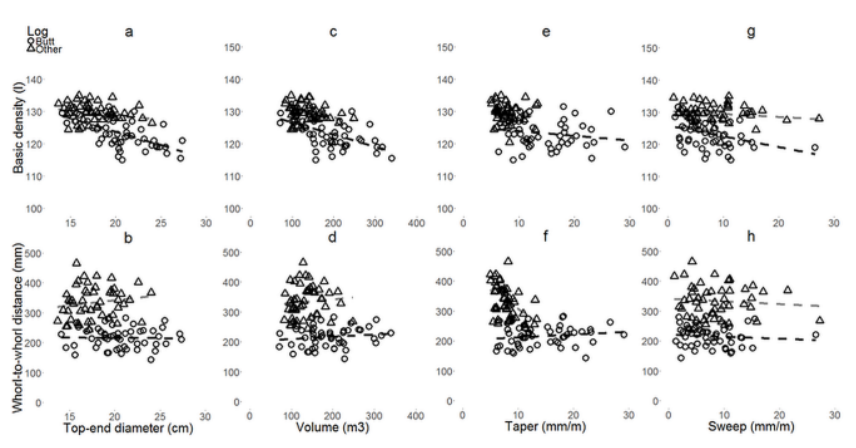

Figure 6. Scatter plots representing the relationship between the terrestrial laser-scanning stemmodel-derived log-specific top-end diameter, volume, taper and sweep and the X-ray scanning derived basic density and whorl-to-whorl distances. The number of butt logs is 52 and other logs 51 . 